\title{
Clinico-pathological classification of rheumatic mitral valve damage and surgical strategy
}

\author{
Tiange Luo, Xu Meng \\ Cardiac Valve Centre, Department of Cardiac Surgery, Beijing Anzhen Hospital, Capital Medical University-Beijing Institute of Heart Lung and \\ Blood Vessel Diseases, Beijing, China \\ Contributions: (I) Conception and design: Both authors; (II) Administrative support: X Meng; (III) Provision of study materials or patients: Both \\ authors; (IV) Collection and assembly of data: T Luo; (V) Data analysis and interpretation: T Luo; (VI) Manuscript writing: Both authors; (VII) Final \\ approval of manuscript: Both authors. \\ Correspondence to: Xu Meng. Cardiac Valve Centre, Department of Cardiac Surgery, Anzhen Hospital, Capital Medical University, No. 2 Anzhen \\ Road, Beijing 100029, China. Email: anzhenarticle@126.com.
}

Background: There is a lack of established pathological indications for rheumatic valve repair. Therefore, we summarized the pathological classifications of rheumatic heart diseases and their correlations with the surgical strategies.

Methods: This observational study enrolled patients with rheumatic heart diseases who underwent mitral valve repair (MVP) or replacement at our centre between January 2017 and January 2019. Mitral leaflet, mitral commissural, and sub-valvular apparatus were classified into three grades from mild to severe, according to their degree of pathological damage. Based on certain principles and the grade of mitral leaflet, mitral commissural, and sub-valvular apparatus damage, three pathological types were identified (types I to III), based on which all patients were classified. The features of each pathological type were summarised. Differences between the three pathological types were analysed using chi-square test of tendency. These data were used to propose a clinico-pathological classification of rheumatic mitral valve damage in Chinese patients.

Results: Of 398 patients, 284 (70\%) underwent MVP for rheumatic mitral valve diseases. There were 58 type I (15\%) patients in the study, all of whom underwent repair (repair rate, 100\%). Preoperative moderateto-severe regurgitation with mild pathological lesions was observed in $64 \%$ of these patients. In 260 type II (65\%) patients, the repair rate was 76\% (197/260); preoperative moderate-to-severe stenosis was observed in $88 \%$ of these patients. In 80 type III (20\%) patients, the repair rate was $36 \%(29 / 80)$; the preoperative rates of extremely severe stenosis and moderate-to-severe regurgitation in these patients were $50 \%$ and $40 \%$, respectively. Several preoperative parameters show the change in trend with the increase in the pathological classification severity.

Conclusions: Our clinico-pathological classification of rheumatic mitral valve damage is applicable to MVP. Considering that the classification principles are based on the possibility of mitral repair, it provides a phased and achievable target ratio for MVP and a principle of screening patients who should undergo rheumatic MVP.

Keywords: Pathological classification; rheumatic mitral valve disease; mitral valve repair (MVP); surgery strategy

Submitted Dec 06, 2020. Accepted for publication Mar 25, 2021.

doi: $10.21037 /$ jtd-20-3456

View this article at: http://dx.doi.org/10.21037/jtd-20-3456 


\section{Introduction}

Rheumatic mitral valve disease is the most common indication for mitral valve surgery, and its prevalence is high in China (1-3). Annually, approximately 20,000 patients in China undergo mitral valve surgery with extracorporeal circulation for rheumatic disease (4,5). An increasing number of surgeons agree that mitral valve repair (MVP) is superior to replacement, even for rheumatic disease (6-8). Although rheumatic MVP is performed in China, the overall ratio of repair to replacement is low $(9,10)$. The lack of established pathological indications for rheumatic valve repair is the main impediment to increasing the number of repairs. Several pathological criteria regarding rheumatic mitral valves include the Wilkins score (11), which is appropriate for percutaneous balloon mitral valvuloplasty but not for surgery, and the pathological grading system for rheumatic mitral valve lesions (12), which was proposed by our centre and has an exhaustive content, can be extremely complicated, but has limited clinical practical applicability. Rheumatic MVP has been performed for 8 years at our centre in more than 600 patients. In this study, we aimed to create a definitive and applicable pathological classification system based on its correlation to selected surgical strategies.

We present the following article in accordance with the STROBE reporting checklist (available at http://dx.doi. org/10.21037/jtd-20-3456).

\section{Methods}

The study design was approved by the ethics review board of the Beijing Anzhen Hospital affiliated with the Capital Medical University (approval no. 2020031X) on February 21,2019 . This study was conducted in accordance with the principles of the Declaration of Helsinki (as revised in 2013) and its later amendments. No patient identification details were used in this study, and informed consent was obtained from all individual participants. There was no specific funding for this study, and there are no competing interests to declare.

\section{Patients}

A total of 398 patients with rheumatic heart diseases who underwent MVP or valve replacement at the Cardiac Valve Centre at Beijing Anzhen Hospital in Beijing, China, between January 2017 and January 2019 were enrolled in this study. All repair patients underwent MVP according to a 'four-step' procedure (Video 1), which included shaving, checking, commissurotomy, and relaxing. We selected one or two letters from each of these words to represent each step (i.e., 'S', 'C', 'O', and ' $R E$ '). Therefore, we named this surgical technique as the 'SCORE' procedure.

\section{Measures and procedures}

In this study, the mitral leaflet, mitral commissural, and subvalvular apparatus were classified into three grades from mild to severe, according to their degree of pathological damage. Based on certain principles and the grade of mitral leaflet, mitral commissural, and sub-valvular apparatus damage, three pathological types were identified from type I to III, based on which all the patients were classified. The features of each pathological type were summarised. The differences between the three pathological types were analysed using chi-square test of tendency. These data were used to propose a clinico-pathological classification of rheumatic mitral valve damage in Chinese patients (Table 1).

\section{Pathological classification scheme}

The pathological classification of the leaflet was as follows (Figure 1): class I, wherein the thickened area of the edges is $<1 / 4$ of the anterior leaflet; class II, which was between class I and class III; and class III, wherein the thickened area is $>1 / 2$ of the anterior leaflet (involvement of the transparent zone), or the anterior leaflet area ring size is $<28$. The classification of the commissure was as follows (Figure 1): class I, wherein the length of the commissural fusion is $<1 \mathrm{~cm}$; class II, which was between class I and class III; and class III, wherein both the commissural fusion and length of one commissural fusion is $>1.5 \mathrm{~cm}$, and the calcification area is $>1 \mathrm{~cm}^{2}$. The classification for the subvalvular apparatus was as follows (Figure 1): class I, wherein the length of the main chordae tendineae is $>1 \mathrm{~cm}$ and the sub-valvular chordae tendineae may be thickened, but there is no shortening and fusion; class II, which was between class I and class III; and class III, wherein the sub-valvular apparatus is shortened and severely fused, with a direct fusion of the papillary muscle and commissural leaflets and usually severe calcification over an area $>1 \mathrm{~cm}^{2}$. For each patient, when all three pathological classes (leaflet, commissure, and sub-valvular) were classified as class I, the pathological type was considered type I. When at least one of the three pathological classes was classified as class II, the 
Table 1 The clinico-pathological classification of rheumatic mitral valve damage in Chinese patients.

\begin{tabular}{|c|c|c|c|}
\hline Classification & Type I & Type II & Type III \\
\hline $\begin{array}{l}\text { Commissure and sub- } \\
\text { valvular apparatus }\end{array}$ & $\begin{array}{l}\text { Commissural fusion is mild. The } \\
\text { sub-valvular orifice area also } \\
\text { has mild stenosis. The sub- } \\
\text { valvular chordae tendineae may } \\
\text { be thickened, but there is no } \\
\text { shortening and fusion }\end{array}$ & $\begin{array}{l}\text { There is an obvious commissural } \\
\text { fusion. There may be a single } \\
\text { calcification in the commissure } \\
\text { (calcification area }<1 \mathrm{~cm}^{2} \text { ). The sub- } \\
\text { valvular apparatus is shortened and } \\
\text { fused, but calcifications do not exist }\end{array}$ & $\begin{array}{l}\text { The commissural leaflets and } \\
\text { sub-valvular apparatus are } \\
\text { fused and severely calcified } \\
\text { (calcification area }>1 \mathrm{~cm}^{2} \text { ) }\end{array}$ \\
\hline Ratio of patients & $15 \%$ & $60 \%$ & $25 \%$ \\
\hline Repair possibility & Almost $100 \%$ & $>70 \%$ & Approximately $30 \%$ \\
\hline Repair techniques & The first three steps & The fourth step may be needed & $\begin{array}{l}\text { All four steps/other repair } \\
\text { techniques }\end{array}$ \\
\hline
\end{tabular}

MVOA, mitral valve orifice area.

pathological type was considered type II. When at least two of the three pathological classes were classified as class III, the pathological type was considered type III.

\section{Statistical analysis}

Continuous variables were expressed as mean \pm standard deviation. Discrete variables were presented as percentages. The differences between the three pathological types were observed using chi-square test. The significance level was set at $\mathrm{P}<0.001$. SPSS version 22.0 software (IBM Corp., Armonk, NY, USA) was used for the statistical analyses.

\section{Results}

Of the 398 patients enrolled, 284 (71\%) and 114 (29\%) underwent MVP and replacement, respectively. The number of patients classified as types I, II, and III was 58 [all underwent repair (repair ratio, 100\%)], 260 [197 underwent repair (repair ratio, $76 \%$ )], and 80 [29 underwent repair (repair ratio, 36\%)], respectively (Table 2). In the overall cohort, the average mitral valve orifice area (MVOA), mean age, and repair ratio decreased linearly with increase in the severity of the pathological classification, along with linear increase in the preoperative left atrial anteroposterior diameter (LAAPD), E-wave, and proportion of severe stenosis (Table 2). In patients who underwent repair, the mean age and MVOA decreased linearly with increase in the severity of the pathological classification, along with linear increase in the preoperative LAAPD, E-wave, intraoperative aortic occlusion time, proportion of severe stenosis, proportion of mixed lesions, and application of the complete SCORE procedure (Table 3, Figure 2). This included all 58 type I patients (15\% of the total patients), with a repair rate of $100 \%$. Preoperative moderate-tosevere regurgitation was observed in $64 \%$ of these patients, and the pathological lesions were mild.

There were 260 type II patients (65\%), with a repair rate of $76 \%$ (197/260). Preoperative moderate-to-severe stenosis was observed in $88 \%$ of the patients, and the complete SCORE procedure was required in $80 \%$ of the patients who underwent MVP. There were 80 type III patients (20\%), with a repair rate of $36 \%$ (29/80); the preoperative rates of extremely severe stenosis and moderate-to-severe regurgitation were $50 \%$ and $40 \%$, respectively. The complete SCORE procedure was required for all patients 


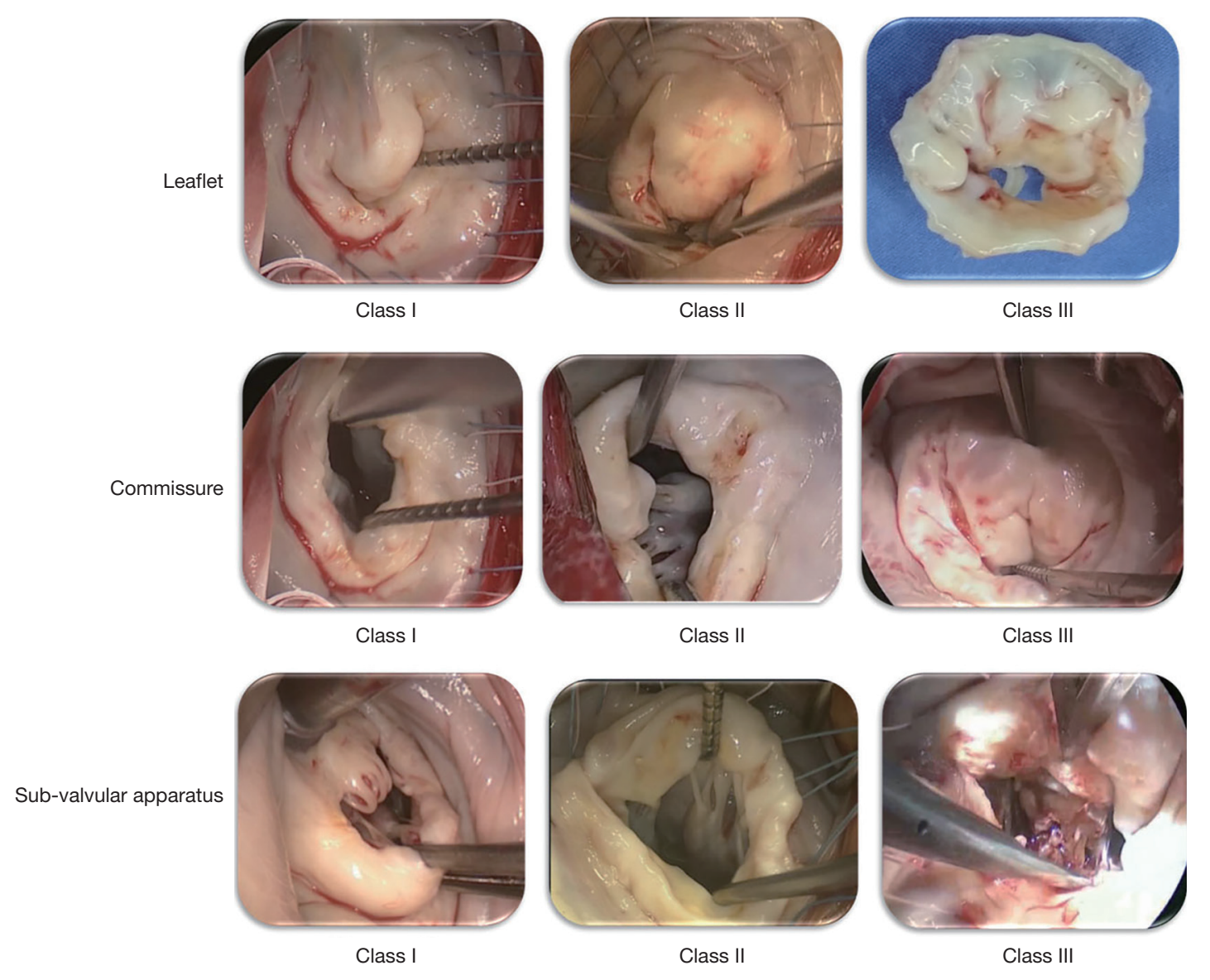

Figure 1 Detailed pathological classification of the leaflet, commissure, and sub-valvular apparatus.

who underwent MVP. Additionally, the repair ratio was higher in men than in type III women (Table 3). The postoperative MVOA and E-wave improved significantly compared with the preoperative values (Table 4, Figures 3,4). Three patients had valve failure: two were type II and one was type III (Table 3).

Based on these results, our centre has perfected the clinico-pathological classification for rheumatic mitral valve damage in Chinese patients (Table 1). We have also proposed a simplified version of the classification system, with three pathological types, for easier use in the clinic (Table 5).

\section{Conclusions}

Our cardiac centre was the first in China to perform rheumatic MVP (13), and it is still regularly performed here. Indeed, more than 150 such surgeries were performed annually at our centre in the last 2 years. Most surgeons at our centre have become proficient in the SCORE procedure for rheumatic MVP, particularly after application of the clinico-pathological classification was initiated. Through the analysis and summary of the clinico-pathological classification, we have deepened our understanding of the pathological characteristics of rheumatic mitral valve disease. Different pathological types present different pathological features. In this work, the number of patients with type II was the highest (65\%) among the three pathological types. The repair ratio of this type was $70 \%$. Although the repair ratio of type I was $100 \%$, the number of type I patients accounted for $15 \%$ of the total number of patients. The number of patients with type III who underwent repair [29/80 (repair ratio: 36\%)] was the lowest among the three pathological types. Therefore, according to these results, type II pathological damage is the most prevalent classification that surgeons face in general. Therefore, the ability of surgeons to proficiently treat type II patients is considered the key to achieving a high repair 
Table 2 Differences between the three types of patients in the overall patient cohort

\begin{tabular}{|c|c|c|c|c|c|}
\hline Parameter & Total & \multicolumn{3}{|c|}{ Pathological classification } & $P$ for trend ${ }^{\dagger}$ \\
\hline Patients (n) & 398 & $58,15 \%$ & $260,65 \%$ & $80,20 \%$ & \\
\hline Female (n, \%) & $285,71.6 \%$ & $47,81 \%$ & $181,69.6 \%$ & $57,71.3 \%$ & 0.219 \\
\hline Age (years) & $52.83 \pm 10.31$ & $57.68 \pm 9.05$ & $50.85 \pm 9.22$ & $55.94 \pm 12.6$ & $<0.001$ \\
\hline E-wave $(\mathrm{m} / \mathrm{s})$ & $189.51 \pm 47.17$ & $163.43 \pm 34.37$ & $191.81 \pm 43.63$ & $201.31 \pm 58.12$ & $<0.001$ \\
\hline Clamping time (min) & $85.46 \pm 25.12$ & $78.79 \pm 21.38$ & $84.7 \pm 23.1$ & $92.75 \pm 31.68$ & 0.004 \\
\hline Mean MVOA $\left(\mathrm{cm}^{2}\right)$ & $1.26 \pm 0.44$ & $1.99 \pm 0.62$ & $1.16 \pm 0.21$ & $1.05 \pm 0.30$ & $<0.001$ \\
\hline $\operatorname{MVOA}(\mathrm{n})\left(1-1.5 \mathrm{~cm}^{2}\right)$ & 258 & 13 & 208 & 37 & 0.051 \\
\hline MR MS (n) (MVOA $<1 \mathrm{~cm}^{2}$ and MR) & 98 & 0 & 76 & 22 & 0.001 \\
\hline Repair ratio & $70 \%, 284 / 398$ & $100 \%$ & $76 \%, 197 / 260$ & $36 \%, 29 / 80$ & $<0.001$ \\
\hline
\end{tabular}

Data are presented as mean \pm SD unless otherwise specified. ${ }^{\dagger} \mathrm{P}$ for trend is calculated using the Chi-square test of tendency that reflects the overall trends between the three pathological classifications. LAAPD, left atrial anteroposterior diameter; MR, mitral regurgitation; MS; mitral stenosis; MVOA, mitral valve orifice area; MVP, mitral valve repair; $n$, number.

Table 3 Differences between the three types of patients that underwent repair.

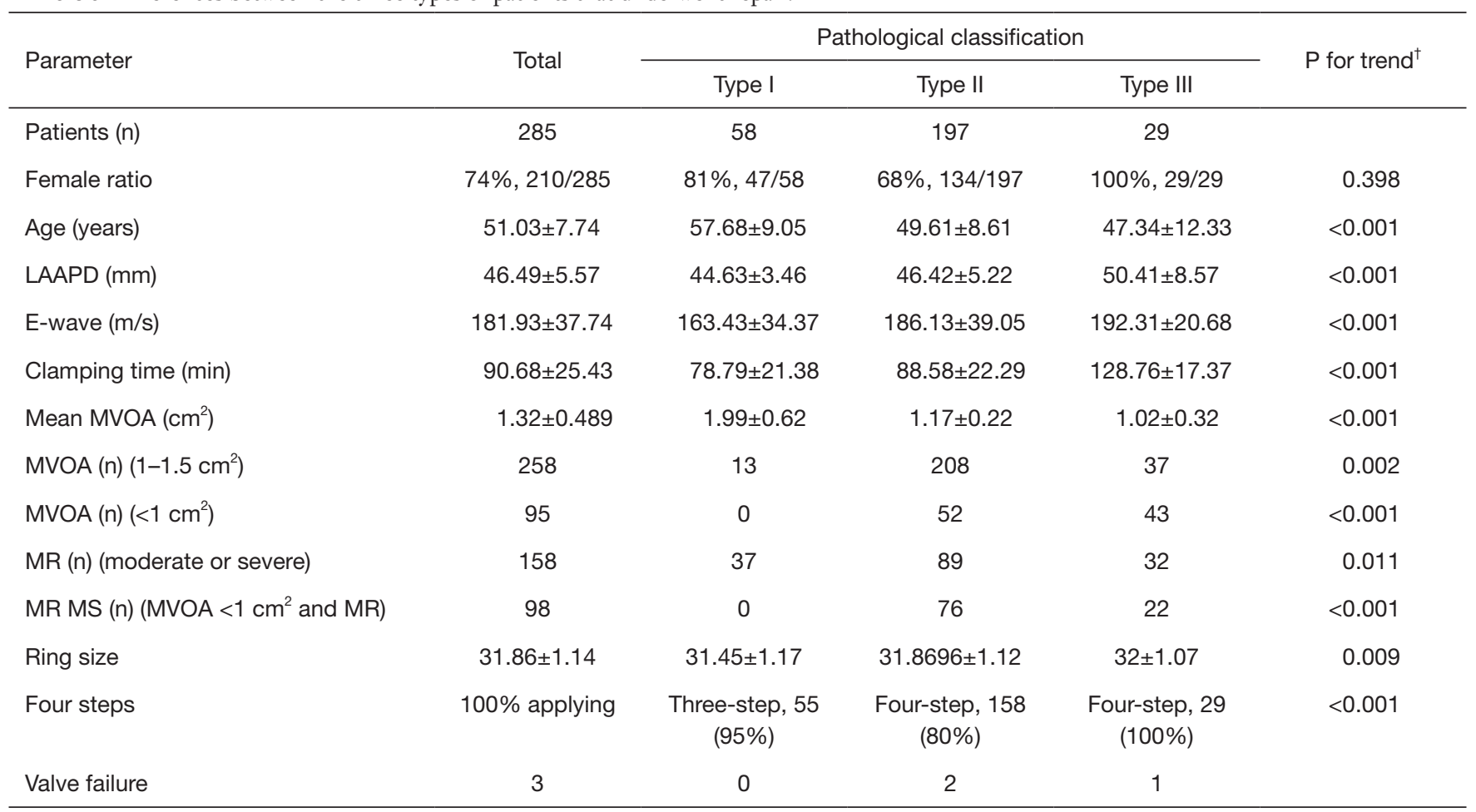

Data are presented as mean \pm SD unless otherwise specified. ${ }^{\dagger} \mathrm{P}$ for trend is calculated using the Chi-square test of tendency that reflects the overall trend between the three pathological classifications. LAAPD, left atrial anteroposterior diameter; MR, mitral regurgitation; MS; mitral stenosis; MVOA, mitral valve orifice area; MVP, mitral valve repair; n, number. 
A

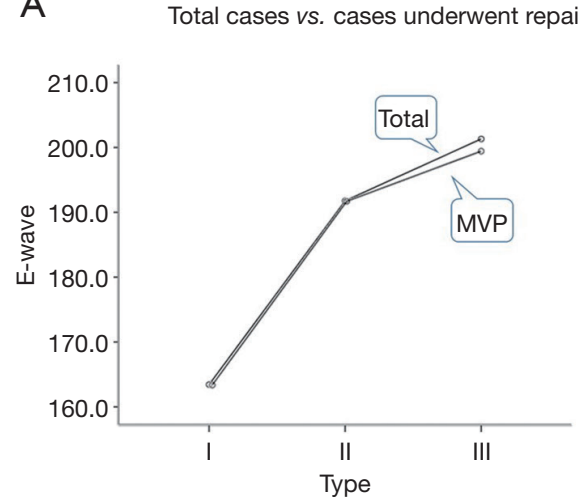

D

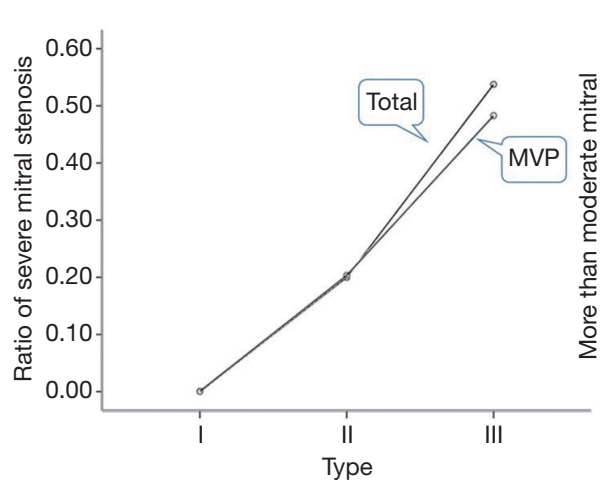

G

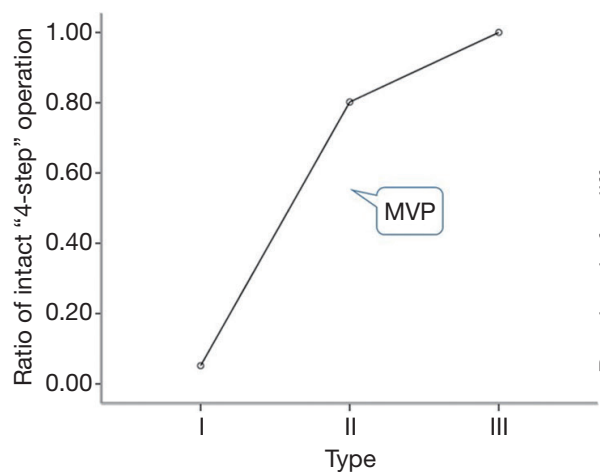

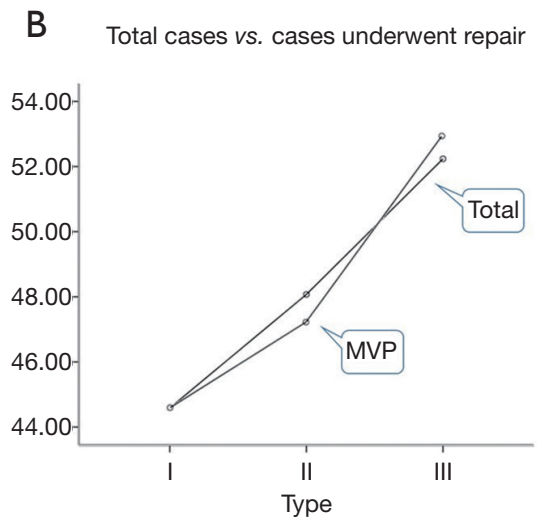

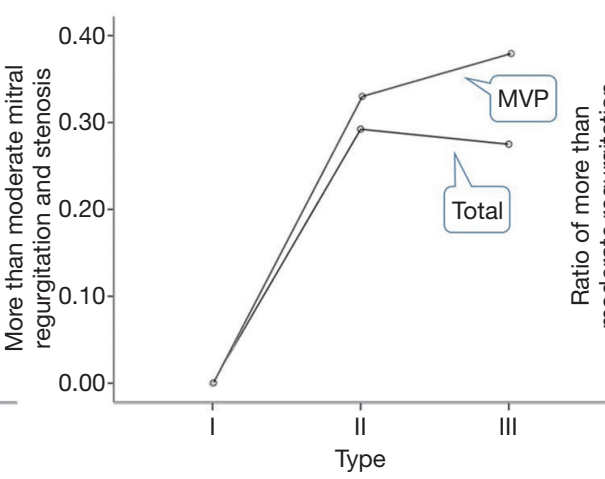

$\mathrm{H}$

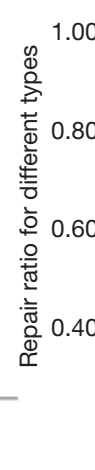

C Total cases vs. cases underwent repair

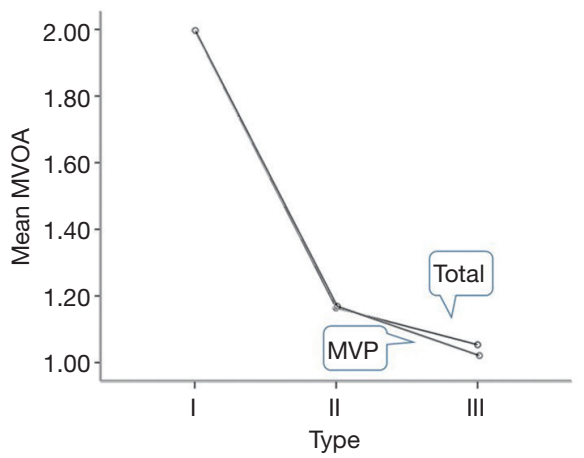

F Total cases vs. cases underwent repair

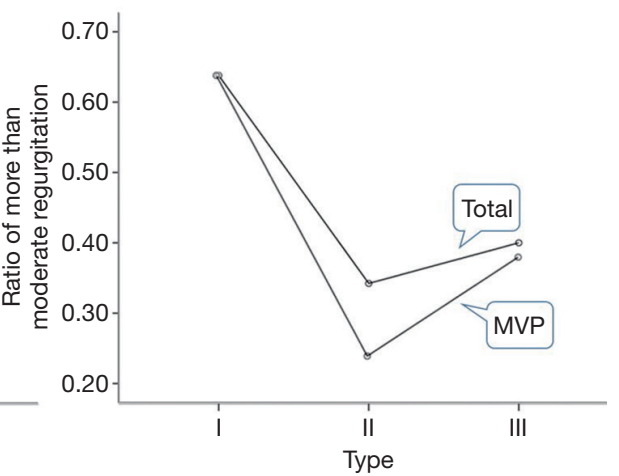

I

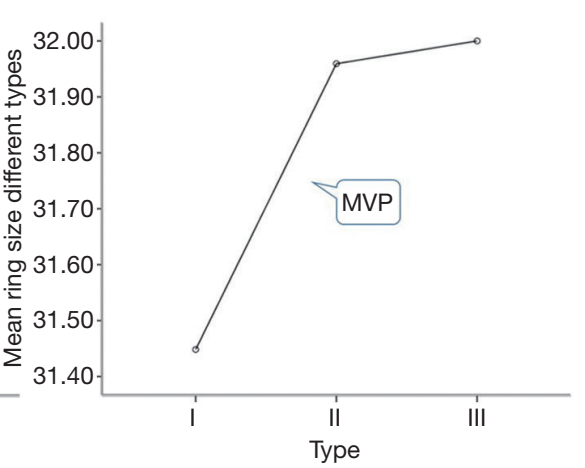

Figure 2 Features of individual pathological types. A strong relationship was observed between the pathological types and surgical strategy. (A) In patients who underwent repair and replacement, the E-wave increased linearly with increase in the severity of the pathological classification; (B) in patients who underwent repair and replacement, the LAAPD increased linearly with increase in the severity of the pathological classification; (C) in patients who underwent repair and replacement, the MVOA decreased linearly with increase in the severity of the pathological classification; (D) in patients who underwent repair and replacement, the proportion of severe stenosis increased linearly with increase in the severity of the pathological classification; (E) in patients who underwent repair and replacement, the proportion of mixed lesions increased linearly with increase in the severity of the pathological classification; (F) in patients who underwent repair and replacement, the proportion of more than moderate regurgitation decreased linearly with increase in the severity of the pathological classification; $(\mathrm{G})$ in patients who underwent repair, the application of the complete SCORE procedure increased linearly with increase in the severity of the pathological classification; $(\mathrm{H})$ in patients who underwent repair, the repair ratio decreased linearly with increase in the severity of the pathological classification; (I) in patients who underwent repair, the mean ring size procedure increased linearly with increase in the severity of the pathological classification. 
Table 4 A comparison between preoperative and postoperative results

\begin{tabular}{|c|c|c|c|c|c|c|c|c|c|}
\hline Classification & \multicolumn{3}{|c|}{ Type I } & \multicolumn{3}{|c|}{ Type II } & \multicolumn{3}{|c|}{ Type III } \\
\hline $\operatorname{MVOA}\left(\mathrm{cm}^{2}\right)$ & $1.99 \pm 0.62$ & $2.47 \pm 0.39$ & 0.00 & $1.21 \pm 0.17$ & $2.37 \pm 0.39$ & 0.00 & $0.76 \pm 0.25$ & $2.27 \pm 0.26$ & 0.00 \\
\hline E-wave (m/s) & $159 \pm 25$ & $139 \pm 30$ & 0.00 & $188 \pm 26$ & $140 \pm 26$ & 0.00 & $200 \pm 27$ & $160 \pm 24$ & 0.00 \\
\hline
\end{tabular}

Data are presented as mean \pm SD unless otherwise specified. MVOA, mitral valve orifice area; Pre-op, pre-operation; Post-op, postoperation.

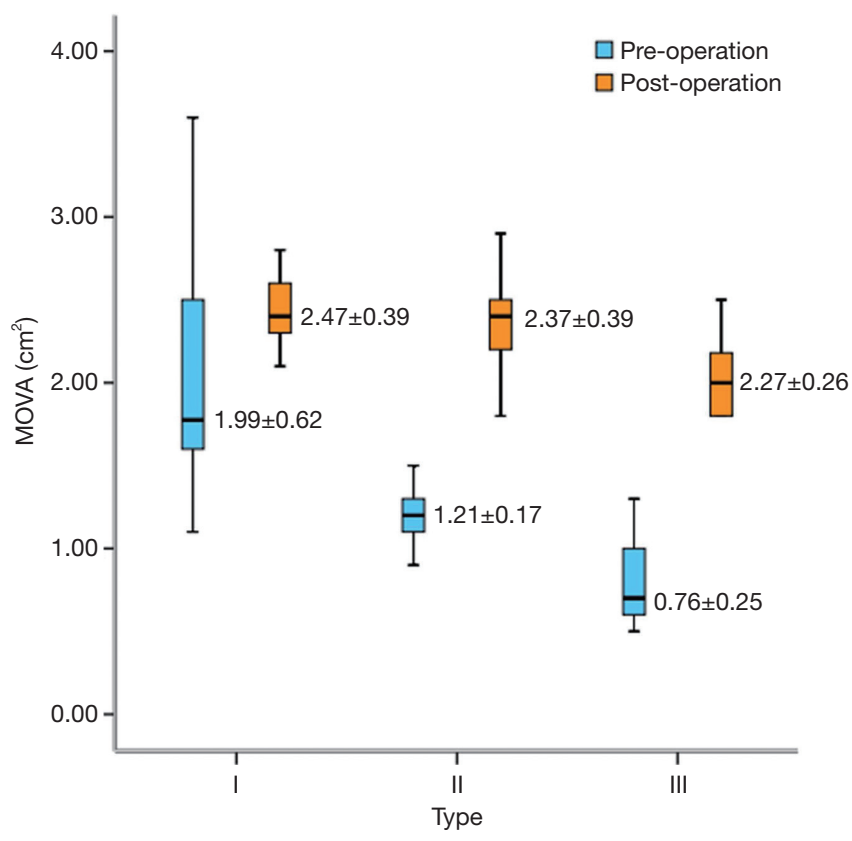

Figure 3 A comparison between preoperative and postoperative mitral valve orifice area (MVOA). The postoperative MVOA improved significantly compared with the preoperative value.

ratio in a cardiac centre.

Further, with increase in the severity of the pathological classification, the degree of mitral valve structural damage significantly increases, along with the difficulty in mitral repair (Tables 1,2). Additionally, there is a strong relationship between the pathological types and surgical strategies. Furthermore, considering that the average patient age was related to the duration of medical history, a younger patient age, along with a high pathological classification grade, indicated a shorter medical history and, possibly, relatively milder pathological damage. Therefore, type I patients are the primary cases that should be seen initially at cardiac centres newly equipped to perform rheumatic MVP. Surgical experience with specific surgical techniques is important in treating type II and higher patients.

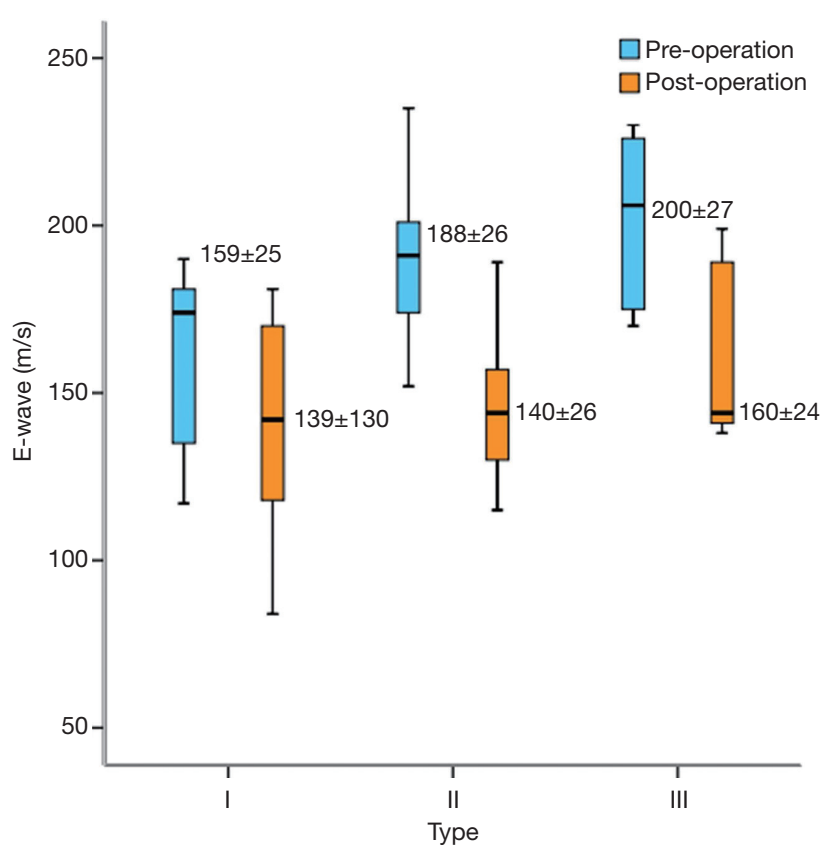

Figure 4 A comparison between preoperative and postoperative E-waves. The postoperative E-wave improved significantly compared with the preoperative value.

Three problems concern cardiac surgeons regarding this topic $(14,15)$ : long-term follow-up results $(8,16)$, repair technique $(13,17)$, and pathological features that can indicate the requirements for repair $(18,19)$. Interestingly, satisfactory follow-up results have been reported at our centre (13) and other cardiac centres $(7,12)$. The majority of patients in these reports underwent successful valve repair at our centre with the SCORE procedure and without the use of other techniques $(13,20)$. However, the performance of other repair techniques has also been reported (21). The lack of established pathological features in this field has been the main impediment to popularising and advancing the rheumatic MVP surgical technique $(18,21)$. Our clinicopathological classification provides a step-by-step path for rheumatic MVP in China. Type I patients can be easily 
Table 5 Simplified version of the three pathological types

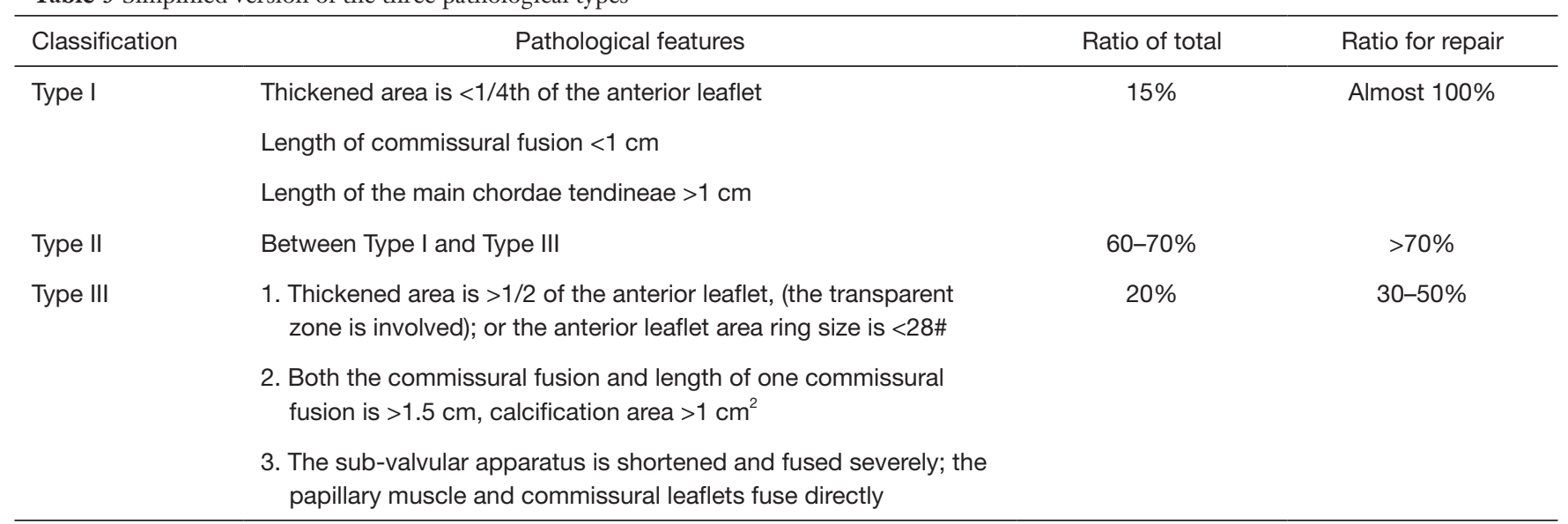

treated, and almost any cardiac surgeon can perform the surgery using the first three steps. Type II patients are more technically demanding, and the surgery could be complex. After an initial learning curve, most surgeons can perform the four steps of the surgery, allowing most type I and II patients to undergo successful repair with the SCORE procedure. In contrast, treatment of most type III patients is challenging, as more senior and experienced surgeons are preferable. We believe that when the SCORE procedure is effectively implemented, the repair rates can be increased by $50-80 \%$ at most cardiac centres in China. Therefore, the SCORE procedure and clinico-pathological classification of rheumatic mitral valve damage form an integrated surgical procedure that can be successfully applied for rheumatic MVP.

This study is limited by its single-centre design and low number of cases. Our findings are susceptible to referral bias and institution-specific practices. Further studies with a longer follow-up period are warranted.

In China, the population of patients that require MVP is large, but the rates of repair are quite low. Therefore, improved strategies for rheumatic MVP are warranted. The clinico-pathological classification of rheumatic mitral valve damage is applicable to MVP as it is simplified and explicit. Since its principles are based on the possibility of mitral repair, this classification system provides a phased and achievable target ratio for MVP and a principle of screening patients who should undergo rheumatic MVP.

\section{Acknowledgments}

We thank Jin Zhao for the excellent contribution to the language editing.

Funding: None.

\section{Footnote}

Reporting Checklist: The authors have completed the STROBE reporting checklist. Available at http://dx.doi. org/10.21037/jtd-20-3456

Data Sharing Statement: Available at http://dx.doi. org/10.21037/jtd-20-3456

Conflicts of Interest: Both authors have completed the ICMJE uniform disclosure form (available at http://dx.doi. org/10.21037/jtd-20-3456). The authors have no conflicts of interest to declare.

Ethical Statement: The authors are accountable for all aspects of the work in ensuring that questions related to the accuracy or integrity of any part of the work are appropriately investigated and resolved. The study was conducted in accordance with the Declaration of Helsinki (as revised in 2013). The study was approved by the ethics review board of the Beijing Anzhen Hospital affiliated with the Capital Medical University (no. 2020031X), and informed consent was obtained from each participant.

Open Access Statement: This is an Open Access article distributed in accordance with the Creative Commons Attribution-NonCommercial-NoDerivs 4.0 International License (CC BY-NC-ND 4.0), which permits the noncommercial replication and distribution of the article with the strict proviso that no changes or edits are made and the original work is properly cited (including links to both the formal publication through the relevant DOI and the license). See: https://creativecommons.org/licenses/by-nc-nd/4.0/. 


\section{References}

1. Watkins DA, Johnson CO, Colquhoun SM, et al. Global, regional, and national burden of rheumatic heart disease, 1990-2015. N Engl J Med 2017;377:713-22.

2. Marijon E, Mirabel M, Celermajer DS, et al. Rheumatic heart disease. Lancet 2012;379:953-64.

3. Rothenbühler M, O'Sullivan CJ, Stortecky S, et al. Active surveillance for rheumatic heart disease in endemic regions: a systematic review and meta-analysis of prevalence among children and adolescents. Lancet Glob Health 2014;2:e717-26.

4. Nobuyoshi M, Arita T, Shirai S, et al. Percutaneous balloon mitral valvuloplasty: a review. Circulation 2009;119:e211-9.

5. Zhimin W, Yubao Z, Lei S, et al. Prevalence of chronic rheumatic heart disease in Chinese adults. Int J Cardiol 2006;107:356-9.

6. Krishna Moorthy PS, Sivalingam S, Dillon J, et al. Is it worth repairing rheumatic mitral valve disease in children? Long-term outcomes of an aggressive approach to rheumatic mitral valve repair compared to replacement in young patients. Interact Cardiovasc Thorac Surg 2019;28:191-8.

7. Dillon J, Yakub MA, Kong PK, et al. Comparative longterm results of mitral valve repair in adults with chronic rheumatic disease and degenerative disease: is repair for "burnt-out" rheumatic disease still inferior to repair for degenerative disease in the current era? J Thorac Cardiovasc Surg 2015;149:771-7.

8. Chemtob RA, Wierup P, Mick S, et al. Choosing the "Best" surgical techniques for mitral valve repair: Lessons from the literature. J Card Surg 2019;34:717-27.

9. Tiange $\mathrm{L}, \mathrm{Xu}$ M. Repair strategies based on pathological characteristics of the rheumatic mitral valve in Chinese patients. Heart Lung Circ 2018;27:856-63.

10. American College of Cardiology/American Heart Association Task Force on Practice Guidelines, Society of Cardiovascular Anesthesiologists, Society for Cardiovascular Angiography and Interventions, et al. ACC/AHA 2006 guidelines for the management of patients with valvular heart disease: a report of the American College of Cardiology/American Heart Association Task Force on Practice Guidelines (writing committee to revise the 1998 Guidelines for the Management of Patients With Valvular Heart Disease): developed in collaboration with the Society of Cardiovascular Anesthesiologists: endorsed by the Society for Cardiovascular Angiography and Interventions and the Society of Thoracic Surgeons. Circulation 2006;114:e84-231.

11. Tomai F, Gaspardone A, Versaci F, et al. Twenty year follow-up after successful percutaneous balloon mitral valvuloplasty in a large contemporary series of patients with mitral stenosis. Int J Cardiol 2014;177:881-5.

12. Yakub MA, Dillon J, Krishna Moorthy PS, et al. Is rheumatic aetiology a predictor of poor outcome in the current era of mitral valve repair? Contemporary longterm results of mitral valve repair in rheumatic heart disease. Eur J Cardiothorac Surg 2013;44:673-81.

13. Luo T, Meng X, Yan Z, et al. Commissuroplasty as a main operative technique in rheumatic mitral valve repair: Surgical experiences and mid-term results. Heart Lung Circ 2020;29:940-8.

14. Schaff HV. Mitral valve repair in patients with rheumatic heart disease: what are the limits? J Thorac Cardiovasc Surg 2015;149:779-80.

15. Remenyi $B$. Rheumatic heart disease of the mitral valve: is there such thing as an ideal operation? Heart Lung Circ 2018;27:779-81.

16. Jiao Y, Luo T, Zhang H, et al. Repair versus replacement of mitral valves in cases of severe rheumatic mitral stenosis: mid-term clinical outcomes. J Thorac Dis 2019;11:3951-61.

17. Mihos CG, Pineda AM, Capoulade R, et al. A systematic review of mitral valve repair with autologous pericardial leaflet augmentation for rheumatic mitral regurgitation. Ann Thorac Surg 2016;102:1400-5.

18. Luo T, Han J, Meng X. Features of rheumatic mitral valves and a grading system to identify suitable repair cases in China. J Thorac Dis 2017;9:3138-47.

19. Li Y, Zhang H, Zhang H, et al. Structural analysis of the mitral valve in rheumatic and degenerative mitral valve diseases: implications for annuloplasty selection. J Cardiovasc Surg (Torino) 2019;60:617-23.

20. Dillon J, Yakub MA, Nordin MN, et al. Leaflet extension in rheumatic mitral valve reconstruction. Eur J Cardiothorac Surg 2013;44:682-9.

21. Kim WK, Kim HJ, Kim JB, et al. Clinical outcomes in 1731 patients undergoing mitral valve surgery for rheumatic valve disease. Heart 2018;104:841-8.

Cite this article as: Luo T, Meng X. Clinico-pathological classification of rheumatic mitral valve damage and surgical strategy. J Thorac Dis 2021;13(5):2933-2941. doi: 10.21037/jtd-203456 